\title{
BASES DE LA TEORÍA POSKEYNESIANA DE DINERO ENDÓGENO
}

\author{
SEBASTIÁN CARVAJAL MANTILLA \\ Flacso-Ecuador
}

Recepción manuscrito: 1 de julio de 2014

Aceptación versión final: 30 de octubre de 2014

\begin{abstract}
RESUMEN Los procesos de creación monetaria en las economías modernas están mal entendidos. Esto lleva a interpretaciones erróneas de cómo funcionan los sistemas monetarios modernos. Los bancos centrales no determinan de manera exógena la cantidad de dinero en una economía. Los bancos privados tienen la capacidad de crear dinero vía crédito y es la demanda de éste la que determina la cantidad de dinero en una economía. El presente artículo pretende explicar de forma sistemática y coherente las bases de la teoría poskeynesiana de dinero endógeno para ilustrar las ideas mencionadas.
\end{abstract}

PALABRAS CLAVE Dinero endógeno, creación monetaria, sistemas monetarios modernos, financiamiento público, poskeynesianismo.

ABSTRACT The process of money creation in modern economies are poorly understood. This leads to misinterpretation of how modern monetary systems work. Central banks do not exogenously determined the amount of money in an economy. Private banks have the ability to create money via credit and the demand for it determines the amount of money in an economy. This article aims to explain in a systematic and consistent basis of post-Keynesian theory of endogenous money to illustrate the ideas mentioned.

KEY WORDS Endogenous money, money creation, modern monetary systems, public financing, post-Keynesian.

JEL CODE E40, E42, E62, E12

\section{INTRODUCCIÓN}

Existen dos concepciones erróneas respecto a la creación monetaria. La primera, y más común, es pensar que los bancos actúan como simples intermediarios, prestando aquellos depósitos que los ahorradores han colocado en sus manos. Bajo este enfoque, los depósitos son creados por las decisiones de ahorro de los hogares, y los bancos simplemente prestan dichos depósitos a los prestatarios. Este enfoque, llamado de fondos prestables, entiende a los bancos como simples intermediarios entre aquellos que buscan ahorrar y aquellos que buscan financiamiento (Keen, 
2014). Si bien los bancos reciben depósitos de los ahorristas, el proceso de emisión de crédito no necesita de ahorros para funcionar. En realidad, los ahorros no aumentan los fondos disponibles para que los bancos puedan emitir créditos. Como se apuntará más adelante, es el acto de emitir un crédito el que crea un depósito, y no al revés como usualmente se piensa.

La segunda concepción errónea es que el banco central, mediante el control de la cantidad de dinero que emite, determina la cantidad de créditos que los bancos pueden otorgar. Éste es el conocido enfoque del multiplicador monetario. Bajo esta visión, el banco central determina una cantidad mínima de reservas que debe poseer un banco y, como el crédito es el resultado de la multiplicación de dichas reservas, basta limitarlas para determinar la cantidad de crédito en una economía. Sin embargo, esta no es una descripción precisa de cómo el crédito es creado en la realidad. En materia de política económica, este enfoque conduce a interpretaciones erróneas acerca de la política monetaria que ejercen los bancos centrales. En realidad, más que controlar la cantidad de reservas, los bancos centrales determinan el precio de dichas reservas, es decir, la tasa de interés; esta es la verdadera herramienta de política monetaria (McLeay, Radia, y Thomas, 2014). Adicionalmente, comprender los procesos de creación monetaria, así como la estructura y funcionamiento de los sistemas monetarios modernos, conduce a nuevas interpretaciones del financiamiento público.

El objetivo de este artículo es desarrollar estas ideas de una forma sistemática, coherente y lo más ilustrativa posible para dejar sentadas las bases de la teoría poskeynesiana de dinero endógeno.

\section{CREACIÓN MONETARIA EN LAS ECONOMÍAS MODERNAS}

La oferta monetaria está compuesta por las especies monetarias en circulación (billetes y monedas) y los depósitos bancarios. Ambos son pasivos financieros de quien los emite y calzan en la definición de dinero porque permiten realizar pagos. De estos dos tipos de dinero, los depósitos bancarios constituyen la gran mayoría. En Ecuador, el 80\% de la oferta monetaria tiene la forma de depósitos bancarios ; en países con sistemas financieros más desarrollados, como Reino Unido, los depósitos alcanzan el 97\% de la oferta monetaria (McLeay, Radia, y Thomas, 2014). Si la oferta monetaria se concentra principalmente en los depósitos bancarios, es su creación la que resulta realmente importante y sensible para una economía.

En la forma en la que depósitos y créditos son creados radica la principal diferencia de la postura poskeynesiana con la economía tradicional. Para esta última, son los depósitos los que permiten emitir créditos; si un banco desea colocar créditos primero deberá recibir depósitos. Bajo el enfoque poskeynesiano la relación camina en sentido opuesto, los depósitos son el resultado de la emisión de crédito por parte de los propios bancos (Lavoie, 2000).

La forma más ilustrativa de explicar la creación monetaria es mediante hojas de balance. Una hoja de balance es un documento contable que registra la cantidad de activos, pasivos y patrimonio que posee cualquier unidad económica - firma, gobierno, banco, cualquier persona, etc.(ver Tabla 1). Existen dos principios fundamentales de la contabilidad financiera. El primero es que las hojas de balance siempre están balanceadas: es decir, los activos siempre son iguales a los pasivos más el patrimonio. Por lo tanto, cualquier cambio en cualquier componente de la hoja 
Tabla 1. Hoja de balance tipo

\begin{tabular}{ll}
\hline ACTIVOS & PASIVOS Y PATRIMONIO \\
\hline Activos financieros & Pasivos financieros \\
Activos reales & Patrimonio \\
\hline
\end{tabular}

Tabla 2. Balance tipo de un banco

\begin{tabular}{ll}
\hline ACTIVOS & PASIVOS Y PATRIMONIO \\
\hline Créditos & Depósitos a la vista \\
Inversiones & Depósitos a plazo \\
Reservas & Otras obligaciones \\
Otros activos & Patrimonio \\
\hline
\end{tabular}

de balance necesariamente genera un cambio similar y que lo compense en cualquier otro componente. El segundo es que todo activo financiero representa siempre un pasivo financiero en otra hoja de balance: «el activo financiero de "uno" es siempre la obligación financiera de "otro"» (Wray, 2012). La hoja de balance de un banco privado, en términos muy generales (ver Tabla 2). Cuando un banco emite un crédito, el beneficiario de dicho crédito (prestatario) recibe los recursos, en forma de depósito, en su cuenta bancaria. Este proceso se registra en las hojas de balance del banco y del prestatario (ver Tabla 3). Este sencillo ejemplo permite realizar un cuestionamiento fundamental: ¿De dónde salió el crédito que ahora permite al prestatario tener dinero? La respuesta a esta pregunta evidencia una diferencia fundamental entre la economía tradicional y la postura poskeynesiana. En la lógica de la economía tradicional, los créditos solo pueden emitirse ante la existencia de depósitos previos. Los bancos son meros intermediarios financieros por lo que necesitan captar recursos para luego colocarlos. Para la economía poskeynesiana la respuesta al cuestionamiento formulado es bastante simple. Los créditos son creados de la nada, de un plumazo o de la mera pulsación de teclado en un computador. Lo único que se necesita es que los bancos consideren solventes a los beneficiarios de los créditos. Los siguientes puntos planteados por Wray (2012) permiten ilustrar la postura poskeynesiana:

- El crédito, y por lo tanto el depósito, son simples registros contables. Por lo tanto, son creados de la nada, ex nihilo. Actualmente, gracias a los avances en las tecnologías de la comunicación e información, el mencionado registro contable es un simple registro electrónico. En la economía moderna, los créditos y los depósitos son creados mediante la mera digitación de un número en una computadora (100, en el ejemplo de la tabla 3).

- Para emitir el crédito, el banco no necesitó dinero en sus bóvedas o en su balance del banco central; es decir, no necesitó reservas. Tampoco necesitó depósitos previos, como sugiere el multiplicador monetario de la economía tradicional.

- Al emitir un crédito el banco no está prestando algo que tenga, simplemente crea dinero en forma de depósitos.

- Los depósitos son una obligación para los bancos, por eso figuran en los pasivos. Al crear 
Tabla 3. Emisión de un crédito de 100 unidades monetarias (UM)

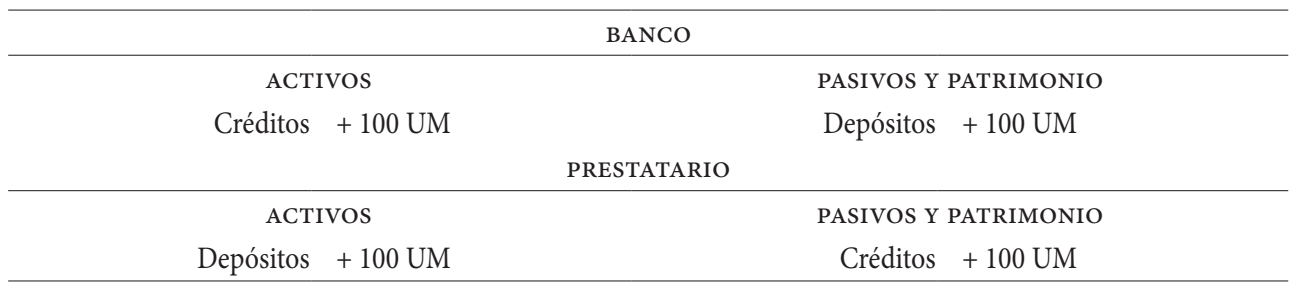

dinero, el banco se compromete a convertir los depósitos en efectivo (billetes y monedas) y a realizar pagos cuando el propietario de la cuenta lo solicite. El banco también se compromete a aceptar sus propias obligaciones emitidas como medio de pago.

Los bancos tienen la capacidad de crear dinero, vía emisión de crédito, porque el dinero es en realidad una simple obligación, un simple pagaré, es crédito, es un instrumento que lleva consigo la promesa de convertirse en algo, pero que además tiene una importante particularidad: sirve, y es socialmente aceptado, como medio de pago ${ }^{2}$.

Bajo el régimen de patrón oro los bancos centrales emitían dinero respaldado en oro, los billetes y monedas eran simples pagarés que servían como medio de pago y a su vez eran convertibles a oro. Al emitir un billete o una moneda, el banco central se comprometía a convertirlo a oro cuando fuere demandado. Lo mismo sucede con los cheques bancarios, por ejemplo. Son también simples pagarés que sirven como medio de pago pero son convertibles a dinero físico a demanda. Los cheques también pueden ser depositados en cuenta, esto no es más que exigir la conversión del cheque en depósito en lugar de convertirlo en billetes y monedas. Lo mismo sucede también con los depósitos bancarios. Son obligaciones de los bancos que sirven como medio de pago. Cuando una persona realiza pagos vía transferencias interbancarias o con tarjetas de débito lo que hace es ordenar al banco que reduzca una cantidad específica de sus depósitos y que los acredite en la cuenta del beneficiario. La condición de convertibilidad también aplica para los depósitos. Cuando el dueño de un depósito retira billetes de un cajero o solicita dinero físico en una ventanilla está exigiendo que su depósito sea convertido a billetes, a dinero físico emitido por los bancos centrales — que es lo que comúnmente se entiende por dinero-. Es importante mencionar que una de las razones más importantes para que el dinero bancario (depósitos) sea aceptado es que los gobiernos y la legislación lo reconocen como medio de pago.

Esta descripción de creación monetaria choca con la noción tradicional de fondos prestables elaborada por la teoría neoclásica, donde los bancos aparecen como meros intermediarios, y multiplicadores, de una cantidad específica de fondos (Keen, 2014).

El proceso descrito aquí es conocido como endogeneidad monetaria. Se habla de endogeneidad porque la cantidad de dinero en una economía responde a la demanda de éste vía crédito, y no a la cantidad que exógenamente fija un banco central. En la medida que exista predisposición de los bancos a emitir créditos y del sector privado (firmas y hogares) por demandar financiamiento el dinero se creará endógenamente (Fullwiler, 2013). 
Uno de los principios fundamentales de la endogeneidad monetaria es que son los créditos los que crean depósitos, y no al revés, como se suele pensar (Fullwiler, 2013). Esto no significa que los bancos no reciban dinero por parte de depositantes. Los bancos de hecho reciben dinero, que de hecho se convierten en depósitos, pero la idea que se quiere transmitir es que éstos no restringen de manera directa la emisión de nuevo crédito o creación monetaria.

Bajo esta lógica, y como Minsky varias veces apuntó (ver, i. e., Minsky, 1986), quien sea puede crear dinero, el problema es que éste sea aceptado. Los gobiernos brindan protecciones específicas a los bancos, lo cual contribuye de manera significativa para que su dinero sea ampliamente aceptado. Son las leyes las que permiten que los cheques y tarjetas de crédito y débito sean aceptados como medio de pago. Además, los bancos son las únicas instituciones del sector privado que tienen acceso directo al banco central, lo cual genera confianza. Los bancos son especiales y tienen la capacidad de que su dinero sea socialmente aceptado porque están respaldados por los gobiernos soberanos ${ }^{3}$ (McCulley, 2009).

\section{LAS TRANSACCIONES EN LOS SISTEMAS MONETARIOS MODERNOS}

Una vez que el dinero es creado el beneficiario lo podrá utilizar para efectuar cualquier tipo de pago. Las transacciones resultantes de los diferentes pagos necesariamente se registran en las hojas de balance de todos aquellos que participen de la transacción. El gasto de cualquier unidad económica es siempre el ingreso de otra, y viceversa. Por ejemplo, la compra de un bien necesariamente se reflejará en la hoja de balance de vendedor y comprador respectivamente. El comprador disminuirá sus activos financieros (depósitos) y aumentará sus activos reales (bienes comprados), y el vendedor hará lo contrario (ver Tabla 4).

Como se usan depósitos bancarios para la transacción, ésta también se registra en la hoja de balance del banco. Cuando tanto comprador como vendedor son clientes del mismo banco, la transacción solo registra un cambio en la composición de los pasivos del banco, esto es, la disminución de los depósitos del comprador y el aumento de los depósitos del vendedor (ver Tabla 5).

En las economías modernas existen varios bancos y las transacciones ocurren a menudo entre clientes de diferentes bancos. Cuando una persona realiza una transferencia interbancaria está ordenando a su banco reducir sus depósitos en una cantidad específica y transferirlos a otro banco. El banco receptor recibe la orden de acreditar la transferencia en la cuenta del beneficiario final. La transacción entre bancos se compensa vía reservas, que son otro tipo de activo para los bancos. Cuando se efectúa un pago interbancario, o se deposita un cheque de otro banco, el banco del comprador registra una disminución en sus depósitos lo cual se compensa con una caída de sus reservas, así la hoja de balance se mantiene balanceada. Estas reservas son transferidas al banco del vendedor lo cual aumenta su activo y permite aumentar su pasivo (depositando los recursos en la cuenta del vendedor) manteniendo igualmente el balance (Fullwiler, 2013). La transacción sugerida se registra en el balance de los bancos privados (ver Tabla 6).

De este simple ejemplo se puede observar cuál es la verdadera función de las reservas: garantizar los pagos interbancarios. Un concepto equívoco es que los bancos prestan sus reservas, concepto que adscribe a la idea del multiplicador monetario donde la cantidad de crédito 
Tabla 4. Compra de un bien

\begin{tabular}{rcc}
\hline & COMPRADOR \\
\hline ACTIVOS & & PASIVOS Y PATRIMONIO \\
Depósitos & -100 & Sin varación \\
Bienes (comprados) & +100 & \\
& VENDEDOR & \\
\hline ACTIVos & & PASIVOS Y PATRIMONIO \\
Depósitos & -100 & Sin varación \\
Bienes (comprados) & +100 & \\
\hline
\end{tabular}

Tabla 5. Movimientos en el balance de un banco por una transacción entre sus clientes

\begin{tabular}{cc}
\hline & COMPRADOR \\
\hline ACTIVos & PASIVOS Y PATRIMONIO \\
Sin varación & Depósitos comprador -100 \\
Bienes (comprados) +100 & Depósitos vendedor +100 \\
\hline
\end{tabular}

Tabla 6. Movimientos en balances bancarios

\begin{tabular}{cc}
\hline & BANCO DEL COMPRADOR \\
\hline ACTIVOS & PASIVOS Y PATRIMONIO \\
Reservas -100 & Depósitos comprador -100 \\
Bienes (comprados) +100 & \\
\hline \multicolumn{2}{c}{ BANCO DEL VENDEDOR } \\
\hline Reservas +100 & PASIVOS Y PATRIMONIO \\
\hline
\end{tabular}

es el resultado de la multiplicación de reservas que posee un banco. Las reservas (o balances de reservas) son las cuentas que tienen los bancos privados en el banco central, iguales a las cuentas que los hogares y las firmas tienen en los bancos privados. No son los fondos disponibles, en caja o en bóvedas, que eventualmente podrían prestarlos. Los bancos solo prestan reservas entre bancos, no al sector privado porque éste no tiene cuentas en el banco central (McLeay, Radia, y Thomas, 2014).

En muchos países existen requerimientos de reservas y, erróneamente, se piensa que esta es la principal herramienta de política monetaria ya que permitiría controlar la cantidad de dinero en una economía. Países como Reino Unido, Australia, Canadá o Nueva Zelanda, no tienen ningún requerimiento de reservas y, obviamente, hay una intensa actividad crediticia que no depende de las reservas bancarias. Bajo el enfoque poskeynesiano, el multiplicador monetario parte de la falacia de que el crédito depende la cantidad de reservas (Fullwiler, 2008).

Cuando un banco no tiene suficientes reservas para liquidar todos los pagos interbancarios que sus clientes han realizado debe acudir al mercado monetario (pedir reservas prestadas a 
otro banco), y en última instancia acudir directamente del banco central. La diferencia, que es importante, radica en que el banco central suele cargar un tipo de interés mayor (de penalización) que la tasa de interés del mercado monetario. La escasez de reservas no significa que un pago no pueda liquidarse, pero los bancos deben prestar atención a la gestión de sus reservas, lo cual implica un límite a la creación de dinero bancario, como se anotará posteriormente.

La descripción del proceso de creación monetaria desarrollada hasta aquí contrasta con la noción tradicional de fondos prestables, donde los bancos son meros intermediarios de fondos (dinero) preexistentes. Sin embargo, el hecho de que los bancos tengan la capacidad de crear dinero de la nada no quiere decir que no existan ciertas limitantes.

\section{LIMITANTES DE LA CREACIÓN MONETARIA BANCARIA}

A pesar de que los bancos crean dinero mediante su comportamiento crediticio, en la práctica existen algunos elementos que restringen la creación ilimitada, los tres más importantes son: 1) el comportamiento propio de los bancos y las fuerzas de mercado que deben enfrentar, 2) el comportamiento del sector privado que solicita financiamiento (firmas y hogares), y 3 ) las herramientas de política monetaria de los bancos centrales (McLeay, Radia, y Thomas, 2014).

La primera limitante viene dada por el nivel de competencia que exista en el mercado bancario. Los bancos deben ser rentables y deben manejar adecuadamente el riesgo asociado a la emisión de crédito; además, el mercado impone ciertas reglas que influyen sobre la rentabilidad y el manejo del riesgo bancario. De forma general, se puede decir que mientras más competitivo es un mercado bancario más limitantes encontrarán los bancos a nivel individual para la creación monetaria (Fullwiler, 2013).

En un mercado bancario competitivo es bastante probable que los depósitos, resultantes de la emisión de crédito, pasen a otros bancos cuando los prestatarios los gasten (como el ejemplo de la tabla 6). Para el banco que emite el crédito, el resultado de dicha emisión serían menos depósitos, menos reservas y más créditos respecto a los depósitos. Esto puede constituir un problema para el banco porque la reducción de reservas incrementa el riesgo de que no pueda cumplir con pagos futuros o incluso que deba acercarse al banco central a solicitar reservas. Como el banco central carga una tasa de interés de penalización para estos préstamos, la rentabilidad del banco puede verse afectada. En mercados bancarios competitivos, los bancos deben asegurarse de atraer o retener depósitos (u otros pasivos) si desean aumentar la emisión de crédito (McLeay, Radia, y Thomas, 2014).

Sin embargo, si el mercado bancario no es competitivo, estas limitantes serán considerablemente menores. Si tanto el comprador como el vendedor son clientes del mismo banco, el banco no perdería el depósito en el momento en que su cliente realice una transacción sino que simplemente lo movería a la cuenta del vendedor (tal como se mostró en la tabla 5). ${ }^{4}$

El manejo adecuado del riesgo, asociado a la emisión de créditos, es otra de las limitantes a la creación monetaria bancaria, que proviene de su propio comportamiento del sistema bancario. El problema con el manejo del riesgo es que está anclado a las expectativas de los bancos. La postura poskeynesiana toma el principio de incertidumbre de Keynes como un hecho de la vida real: el futuro es incierto porque los eventos que transcurren en el tiempo real no 
Tabla 7. Balance tipo de un banco central

\begin{tabular}{ll}
\hline ACTIVOS & PASIVOS Y PATRIMONIO \\
\hline Instrumentos del mercado de crédito & Dinero en circulación \\
Préstamos a bancos locales & Reservas bancos locales \\
Oro y moneda extranjera & Cuenta del tesoro (Min. Finanzas) \\
Otros activos financieros & Cuentas de extranjeros \\
Activos reales & Otros pasivos y patrimonio \\
\hline
\end{tabular}

Tabla 8. Movimientos en balances por transferencias interbancarias

\begin{tabular}{|c|c|}
\hline \multicolumn{2}{|c|}{ ESCENARIO 1} \\
\hline \multicolumn{2}{|c|}{ BANCO CENTRAL } \\
\hline ACtivos & PASIVOS Y PATRIMONIO \\
\hline Sin varación & Reservas banco C -100 \\
\hline & Reservas banco V - 100 \\
\hline \multicolumn{2}{|c|}{ ESCENARIO 2} \\
\hline \multicolumn{2}{|c|}{ BANCO C } \\
\hline \multicolumn{2}{|r|}{ PASIVOS Y PATRIMONIO } \\
\hline Reservas +100 & Préstamo de banco $\mathrm{P}-100$ \\
\hline \multicolumn{2}{|c|}{ BANCO P } \\
\hline ACTIVOS & PASIVOS Y PATRIMONIO \\
\hline Crédito a banco $C+100$ & Sin varación \\
\hline Reservas -100 & \\
\hline \multicolumn{2}{|c|}{ BANCO CENTRAL } \\
\hline \multicolumn{2}{|r|}{ PASIVOS Y PATRIMONIO } \\
\hline \multirow[t]{2}{*}{ Sin varación } & Reservas banco $C+100$ \\
\hline & Reservas banco P - 100 \\
\hline \multirow[t]{3}{*}{ Sin varación } & Reservas banco C -100 \\
\hline & Reservas banco V + 100 \\
\hline & \\
\hline \multicolumn{2}{|c|}{ ESCENARIO 3} \\
\hline ACtIVOS & PASIVOS Y PATRIMONIO \\
\hline Reservas +100 & Préstamo Banco Central +100 \\
\hline \multicolumn{2}{|c|}{ BANCO CENTRAL } \\
\hline ACTIVOS & PASIVOS Y PATRIMONIO \\
\hline \multirow[t]{3}{*}{ Crédito banco $\mathrm{C}+100$} & Reservas banco $C+100$ \\
\hline & Reservas banco C -100 \\
\hline & Reservas banco $\mathrm{V}+100$ \\
\hline
\end{tabular}


obedecen a distribuciones de probabilidad anticipadas. La incertidumbre que impregna la economía se debe a la imposibilidad de asegurar que los modelos, en los que una unidad se basa para tomar una decisión, sean validados en el futuro (Minsky, 1996).

Las expectativas que tengan los bancos sobre el futuro o sobre la rentabilidad de un negocio influyen en la decisión de aprobar un crédito o no, por esta razón su comportamiento y expectativas inciden en la creación de dinero.

La segunda limitante importante es el comportamiento del sector privado (firmas y hogares), son éstos quienes en última instancia deciden tomar un crédito. Es verdad que con el manejo de los tipos de interés (además de prácticas de marketing), el banco central, como los bancos privados, puede inducir al sector privado a solicitar un crédito. Sin embargo, la decisión final recae en hogares y firmas. Las expectativas juegan un rol fundamental aquí. Cuando no existen expectativas optimistas sobre las condiciones económicas futuras, tanto el sector privado como el bancario se mostrarán reacios a aceptar/emitir créditos, limitando así la creación de dinero bancario (Minsky, 1986).

La tercera limitante es la política monetaria. Una de las potestades más importantes que tienen los bancos centrales es la de determinar los tipos de interés de corto plazo, específicamente aquella tasa que pagan los bancos comerciales sobre sus reservas. Esto pueden hacerlo porque, en la mayoría de países, los bancos centrales tienen el monopolio en la provisión de dinero. Los cambios en la tasa de interés determinada por el banco central definen un amplio rango de tasas de interés, incluyendo aquellas definidas por los bancos para los préstamos y depósitos. En este sentido, la política monetaria puede limitar la creación monetaria bancaria a través de la determinación del precio del crédito (McLeay, Radia, y Thomas, 2014).

Los bancos centrales no suelen determinar una cantidad específica de reservas para alcanzar los tipos de interés de corto plazo, como sugiere el enfoque de fondos prestables o del multiplicador monetario. Al contrario, se enfocan directamente en la determinación de dichos tipos de interés (Fullwiler, 2008).

\section{LA INELUDIBLE RESPONSABILIDAD DE SOSTENER EL SISTEMA DE PAGOS}

En la tabla 6 se ilustró cómo los bancos privados liquidan pagos entre sus clientes vía trasferencia de reservas. Dichas reservas son cuentas que tienen los bancos privados en el banco central y constituyen parte de sus pasivos. Por lo tanto, la simple transacción del inicio de todo el ejemplo presentado hasta aquí también se registra en la hoja de balance del banco central (ver Tabla 7).

En la tabla 6 se observó cómo se compensan los pagos entre dos bancos vía transferencias de reservas. Como las reservas son cuentas en el banco central, la transacción también se registra en su balance. La liquidación de pagos interbancarios puede darse bajo tres escenarios: 1) que el banco de quien realiza una compra cuente con reservas para transferir al banco de quien realiza la respectiva venta, 2) que el banco del comprador no tenga reservas suficientes y tenga que adquirirlas del mercado interbancario (tomar prestado de otro banco), y 3) que el banco del comprador no tenga reservas ni las haya podido conseguir del mercado interbancario por lo que tendría que acudir, ineludiblemente, al banco central (Fullwiler, 2013). Los 
Tabla 9. Hoja de balance del banco privado

\begin{tabular}{cc}
\hline \multicolumn{3}{c}{ VENTA DE BONOS A LA BANCA PRIVADA } \\
\hline ACTIVOS & PASIVOS Y PATRIMONIO \\
\hline Bonos del gobierno +100 & Depósitos del gobierno +100 \\
& PAGO DE PENSIONES JUBILARES \\
\hline Sin varación & Depósitos del gobierno -100 \\
& Depósitos jubilados +100 \\
\hline
\end{tabular}

Tabla 10. Financiamiento del déficit público (visión poscartalista)

\begin{tabular}{|c|c|c|c|}
\hline \multicolumn{2}{|c|}{ BANCO CENTRAL } & \multicolumn{2}{|c|}{ BANCO PRIVADO } \\
\hline ACTIVOS & PASIVOS & ACTIVOS & PASIVOS \\
\hline & & Bonos Gob. $=100$ & Depósitos Jub. $=100$ \\
\hline \multirow[t]{2}{*}{ Bonos Gob. +10} & Reservas B +10 & Bonos Gob. -10 & Sin variación \\
\hline & & Reservas +10 & \\
\hline \multirow[t]{3}{*}{ Sin variación } & Reservas B -10 & Reservas B -10 & Sin variación \\
\hline & Billetes +10 & Billetes +10 & \\
\hline & & Billetes - 10 & Depósitos Jub. -10 \\
\hline Bonos Gob. $=10$ & Billetes $=10$ & Bonos Gob. $=90$ & Depósitos =90 \\
\hline \multirow[t]{2}{*}{ Bonos Gob. +9} & Reservas B +9 & Bonos Gob. -9 & Sin variación \\
\hline & & Reservas +9 & \\
\hline \multirow[t]{2}{*}{ Bonos Gob. $=19$} & Billetes $=10$ & Bonos Gob. = 81 & Depósitos $=90$ \\
\hline & Reservas B $=9$ & Reservas $=9$ & \\
\hline
\end{tabular}

Tabla 11. Financiamiento del déficit público (visión neocartalista)

\begin{tabular}{|c|c|c|c|}
\hline \multicolumn{2}{|c|}{ BANCO CENTRAL } & \multicolumn{2}{|c|}{ BANCO PRIVADO } \\
\hline ACTIVOS & PASIVOS & ACTIVOS & PASIVOS \\
\hline Bonos Gob. $=100$ & Cuenta Gob. +100 & & \\
\hline \multirow[t]{2}{*}{ Sin variación } & Cuenta Gob. - 100 & Reservas +100 & Depósitos + 100 \\
\hline & Reservas B + 100 & & \\
\hline \multirow[t]{3}{*}{ Sin variación } & Reservas -10 & Reservas - 10 & Depósitos Jub. -10 \\
\hline & Billetes +10 & Billetes +10 & \\
\hline & & Billetes - 10 & \\
\hline \multirow[t]{3}{*}{ Bonos Gob. $=100$} & Cuenta Gob. $=0$ & Reservas $=90$ & Depósitos = 90 \\
\hline & Reservas B $=90$ & & \\
\hline & Billetes $=10$ & & \\
\hline \multirow[t]{2}{*}{ Bonos Gob. -81 } & Reservas B -81 & Reservas - 81 & Sin variación \\
\hline & & Bonos Gob. +81 & \\
\hline \multirow[t]{2}{*}{ Bonos Gob. $=19$} & Billetes $=10$ & Bonos Gob. $=81$ & Depósitos = 90 \\
\hline & Reservas $=9$ & Reservas $=9$ & \\
\hline
\end{tabular}


movimientos que registran las hojas de balance en los tres escenarios se muestran en la tabla 8 (el banco $C$ es el banco del comprador, el banco $V$ es el del vendedor y el banco $P$ es aquel que presta reservas).

El escenario 1 registra solamente la transferencia de reservas del banco $C$ al banco $V$. El escenario 2 registra cómo el banco $C$ toma reservas prestadas del banco $P$ para luego transferirlas al banco $V$. En este escenario, ambas operaciones se registran como transferencias de reservas entre bancos en el banco central. Por último, el escenario 3 muestra cómo el banco $C$ consigue reservas directamente del banco central para luego transferirlas al banco $V$ (ver Tabla 8).

Todas las discrepancias que pueden existir en la obligaciones entre bancos deben saldarse mediante el préstamo de fondos entre bancos, usualmente esto se hace con la ayuda de una cámara de compensación, que es justamente la función que cumplen los bancos centrales (Lavoie, 2000).

Al ser el proveedor de reservas de última instancia, el banco central es el responsable de asegurar la continuidad de las operaciones del sistema de pagos sin interrupciones. Esta no es una responsabilidad menor, puesto que implica garantizar la ejecución de los pagos de una gran cantidad de transacciones, lo cual es indispensable para la estabilidad de las economías modernas (Fullwiler, 2013).

Según datos proporcionados por Fullwiler (2008), es típico observar en varios países OECD que, en promedio, el 17\% del PIB se mueve de manera diaria por los sistemas nacionales de pagos. Es decir, en apenas cinco días pasan por el banco central transacciones equivalentes al valor de la producción de todo un año de estos países. En el caso ecuatoriano, la cantidad de pagos que pasan por el sistema nacional de pagos duplican el PIB en cada año. A pesar de estar dolarizados, esta importante función todavía está en manos del banco central.

La potestad que tiene un banco central para acomodar las necesidades de reservas de los bancos privados, ya sea para cumplir con pagos o requerimientos de ley, existe porque los bancos privados en conjunto no pueden modificar la cantidad de reservas existentes en el sistema monetario. Los bancos pueden prestar o tomar prestadas reservas del mercado monetario, pero esto solo afecta la distribución de reservas existentes, pero no su cantidad. Las reservas bancarias, al ser un pasivo del banco central, pueden ser creadas de forma ilimitada, éstas pueden ser cualquier número (Lavoie, 2000).

Esto explica lo hecho por la Fed, en Estados Unidos, durante los últimos años. Las reservas bancarias en dicho país, que entre 1990 y 2008 oscilaron alrededor de los 83 mil millones de dólares en promedio (alcanzando los 97 mil millones en agosto de 2008), se incrementaron a 2,7 billones entre 2008 y febrero de 2014, un incremento de más de 2.700 por ciento en apenas seis años (FRED, 2014; Wray, 2013)

Resultan bastante ilustrativas las palabras del ex director de la Reserva Federal de los Estados Unidos, Ben Bernanke, a propósito de las ingentes cantidades de dinero que la Fed inyectó a la economía vía reservas bancarias. En una entrevista concedida a CBS en marzo del 2009, dijo:

Entrevistador: ¿Es el dinero de los impuestos el que la Fed está gastando?

Bernanke: No es dinero proveniente de los impuestos. Los bancos tienen cuentas en la Fed de manera muy similar a las cuentas que usted tiene en un banco comercial. Por lo tanto, para prestar reservas a un banco, solamente usamos el computador y marcamos el tamaño de las cuentas que los bancos tienen en la Fed. 
La importancia de los bancos centrales es superlativa para la estabilidad económica. Al vivir en economías de producción monetaria, cuando una economía entra en recesión la acción de las autoridades monetarias es fundamental.

En Europa las autoridades monetarias se han mostrado reacias a implementar políticas como las de la Fed, salvo durante pocas excepciones, lo cual ha llevado a países como Grecia o España a situación de verdadero desastre social. Esta es una lección que la economía ecuatoriana debe seguir muy de cerca, puesto que al estar dolarizados no tenemos un banco central con la capacidad de crear reservas a demanda.

Una característica interesante de los sistemas monetarios modernos es que la cantidad de dinero de alto poder expansivo (billetes y monedas más depósitos en el banco central) no tiene relación alguna con la cantidad total de dinero, o de dinero bancario, en el sistema. En la medida que el sector privado (hogares y firmas) hacen uso de transferencias y tarjetas de crédito o débito para cancelar sus pagos los billetes y monedas pierden importancia, han comenzado a dejar de ser usadas. Cuando el sistema bancario está involucrado en actividades de crédito, la cantidad de dinero de alto poder expansivo es relativamente pequeña, incluso puede acercarse a cero (Lavoie, 2000).

\section{BANCO CENTRAL Y EL FINANCIAMIENTO DEL GOBIERNO}

Al ser la cámara de compensación, sobre el banco central se sostienen todas las transacciones de las economías modernas. Esto incluye también las transacciones del sector público. Bajo el paraguas poskeynesiano de dinero endógeno existen dos visiones relacionadas al financiamiento público. La primera plantea que el Tesoro, el brazo fiscal del gobierno, debe vender bonos a los bancos para obtener financiamiento; la segunda, plantea que debe existir una consolidación entre el Tesoro y el banco central de tal suerte que el gobierno pueda adquirir financiamiento directamente del banco central. La primera visión es conocida como poscartalista (propuesta por Lavoie 2000, 2011) y la segunda como neocartalista (ver Wray, 2012; Tcherneva, 2006; Bell, 2000; Forstater y Mosler, 2005). Para explicar ambos enfoques se usarán ejemplos propuestos por Lavoie (2000) y (2011)

Bajo el lente poscartalista el gasto del gobierno debe buscar financiamiento de forma parecida al del sector privado: las empresas deben solicitar créditos en los bancos para poder realizar sus gastos. Los bonos emitidos por el gobierno y comprados por los bancos privados juegan el mismo rol que los préstamos emitidos a las empresas privadas (Lavoie, 2011).

Si el gobierno necesita incurrir en déficit para cubrir sus gastos deberá adquirir financiamiento. Se supone que requiere de 100 UM para cumplir con pagos por pensiones jubilares. Para esto emite bonos por $100 \mathrm{UM}$ que son colocados en la banca privada. Una vez que la banca privada adquiere el bono acredita a la cuenta del gobierno la cantidad de $100 \mathrm{UM}$, ahora el gobierno cuenta con depósitos que los usa para pagar las pensiones jubilares. En primera instancia se contabiliza la adquisición del activo y generación del depósito en la cuenta del gobierno y posteriormente, el pago de pensiones jubilares, se transfieren los recursos de la cuenta del gobierno a la cuenta de los beneficiarios de las pensiones, lo cual no es más que un cambio en la composición de los pasivos de la banca privada (ver Tabla 9). 
Para dotarle de mayor realismo al ejemplo, se supone que los beneficiarios de las pensiones jubilares desean tener 10 UM en efectivo (billetes y monedas) y el resto en depositado en el banco. ¿De dónde saca el banco privado las 10 UM en efectivo? Debe acudir al banco central, pero no debe endeudarse con éste para adquirir los billetes, solamente debe venderle cierta parte de los bonos del gobierno que previamente adquirió. Los bonos del gobierno son activos para el banco central también (están en la cuenta instrumentos de mercado de crédito en la tabla 7) por lo tanto, con su adquisición puede emitir pasivos, que en este caso son sus billetes y monedas. Las compras de bonos del tesoro a bancos privados por el banco central es lo que se conoce como operaciones de mercado abierto.

En el presente ejemplo, la banca privada vende al banco central bonos del gobierno por el valor de 10 UM consiguiendo así reservas bancarias por el mismo valor, lo cual se registra en el balance del banco central como un aumento de bonos del gobierno por el lado del activo y como aumento de reservas bancarias en el pasivo (segunda fila, tabla 10). En el balance del banco privado se registra el cambio en la composición de los activos (10 UM menos en forma de bonos del gobierno y 10 UM más en forma de reservas). Posteriormente el banco privado solicita al banco central dinero en efectivo, por lo tanto cambia la composición del pasivo del banco central (cambio de reservas por billetes) y la composición del activo del banco privado (cambio de reservas por billetes), como se muestra en la tercera fila de la tabla 10. De esta forma el banco privado posee el dinero en efectivo necesario para los jubilados quienes retiran del banco $10 \mathrm{UM}$ en efectivo (cuarta fila, tabla 10). Al final de estas transacciones las hojas de balance del banco central y banco privado se ilustran en la quinta fila de la tabla 10.

Por último, la mayoría de países exigen requerimientos de reservas a la banca privada, esto suele ser un determinado porcentaje de los depósitos. Sin embargo, esto no sucede en todos los países, Reino Unido, Canadá o Nueva Zelanda, son ejemplos de países donde no existen requerimientos de reserva (Fullwiler, 2008). Para este ejemplo se supone también que existen requerimientos de reserva del 10\% de los depósitos. La banca privada se ve obligada a vender nuevamente bonos del gobierno al banco central para adquirir las reservas que la ley le exige. Como los depósitos se encuentran en 90 UM el banco adquiere reservas por 9 UM y así satisface el requerimiento legal (sexta fila, tabla 10). El balance final del banco central y del banco privado se muestra en la última fila de la tabla 10.

El enfoque neocartalista propone una variación al poscartalista que radica en la consolidación del Tesoro y banco central. De esta forma, los bonos del gobierno adquiridos por directamente por el banco central (primera fila, tabla 11). Posteriormente, el gobierno transfiere los recursos a las cuentas de los beneficiarios de las pensiones jubilares. En términos operativos lo que sucede es que el gobierno transfiere los recursos de su cuenta en el banco central a las cuentas de los bancos privados dotándoles así de reservas que permiten depositar en las cuentas que los beneficiarios de las pensiones tienen en los bancos privados (segunda fila tabla 11). Como los jubilados desean poseer 10 UM en efectivo el banco privado debe solicitarlo al banco central. Esto lo hace utilizando sus reservas, adquiere billetes que los pasa directamente a los jubilados (tercera fila tabla 11). El resultado hasta aquí es que el banco central posee $100 \mathrm{UM}$ en bonos del gobierno y por el lado del pasivo 90 UM en reservas bancarias y ha colocado 10 
UM en billetes; por su parte, el banco privado posee 90 UM en reservas y 90 UM en depósitos (cuarta fila, tabla 11). Como existe un requerimiento de reservas del 10\% de los depósitos el banco privado tiene $81 \mathrm{UM}$ como exceso en reservas. A los bancos privados no les conviene tener reservas en exceso puesto que éstas son un activo que no devenga ningún tipo de rentabilidad. Por esta razón prefieren poseer bonos del gobierno a poseer reservas que no devengan ningún tipo de rentabilidad, o una muy inferior a la de los bonos del gobierno. El banco privado mantiene 9 UM en reservas para cumplir el requerimiento legal y las 81 UM restantes las invierte en bonos del gobierno que son adquiridos del banco central mediante operaciones de mercado abierto (quinta fila, tabla 11). El resultado final de estas transacciones se muestra en la última fila de la tabla 11.

El resultado final del ejemplo poscartalista y neocartalista es exactamente el mismo. La única diferencia es el diseño institucional. En la mayoría de países la visión neocartalista no aplica porque los bancos centrales no pueden adquirir bonos de los gobiernos centrales de manera directa, esto es conocido como independencia del banco central (Wray, 2007).

La otra cara de la moneda de dicha independencia es que los gobiernos caen en una dependencia de la banca privada. En mercados financieros competitivos dicha dependencia es menor, pero si no hay suficiente competencia ${ }^{5}$ los bancos tienen un enorme poder fáctico sobre los gobiernos puesto que su financiamiento dependerá de éstos.

Una de las conclusiones más potentes de esta forma de entender el funcionamiento de los sistemas modernos es que no hay razón alguna para que los gastos del gobierno fluctúen. Ante épocas de recesión o de disminución de ingresos públicos, el gobierno siempre puede financiar su gasto vía déficit de la forma ilustrada aquí. La economía tradicional teme al sobreendeudamiento público porque carece de una comprensión adecuada de cómo operan en realidad los sistemas monetarios. Un gobierno jamás puede caer en default de su deuda, en la medida que su deuda esté denominada en moneda nacional. Cualquier unidad económica puede emitir sus pasivos en cantidades ilimitadas, todas las transacciones de las economías modernas se sostienen en pasivos del banco central, por lo tanto estás no pueden acabarse. Esta es la razón por la cual los gobiernos siempre pueden hacer frente a sus deudas si éstas están denominadas en moneda local. Los países sin soberanía monetaria no solo han renunciado a las herramientas monetarias, sino a las fiscales también. Esto se conoce también como financiamiento funcional (Lerner, 1943 y Forstater, 1999).

\section{CONCLUSIONES}

La teoría poskeynesiana propone una forma coherente de entender el funcionamiento de sistemas monetarios modernos. Entre las principales conclusiones de este enfoque se hallan las siguientes:

- Los bancos privados crean dinero «de la nada». Es la emisión de créditos la que da lugar a los depósitos y no al revés, como usualmente se entiende. Los bancos no son meros intermediaros de recursos como supone el enfoque de fondos prestables de la economía tradicional.

- La actividad bancaria se sostiene en el banco central. Ésta institución tiene la ineludible tarea 
de garantizar que todos los pagos interbancarios de realicen sin interrupciones. Esta no es una responsabilidad menor dado que de ésta depende la estabilidad económica.

- El enfoque poskeynesiano de dinero endógeno permite analizar de forma heterodoxa el financiamiento público. El sobreendeudamiento y el miedo a un default de la deuda pública es un fantasma inexistente puesto que el banco central de cualquier país siempre podrá garantizar el pago de cualquier deuda. Esto no aplica para países sin soberanía monetaria lo que sugiere que la renuncia a la soberanía monetaria es también renuncia a la soberanía fiscal. El caso español y griego dicen mucho, y el Ecuador debería observar con preocupación dichos procesos.

Por último, lo propuesto en este artículo debe ser tomado como un prerrequisito para avanzar en discusiones más profundas sobre política económica, política monetaria, política fiscal, inflación, empleo, crisis financieras, economías abiertas y todo el complejo entramado que implican las economías modernas. Ojalá se contribuya a lo dicho.

\section{NOTAS}

1 Se tomó como oferta monetaria a la variable liquidez total de los boletines estadísticos del Banco Central del Ecuador.

2 El objetivo de este artículo no es discutir qué es el dinero. Por tal razón no se ahonda en el tema. Sin embargo, si el lector desea consultar estos enfoques (cartalista y neocartalista), puede revisar Innes (1913, 1914), Knapp (1924), Bell (2001), Tcherneva (2006), Wray (2010).

$3 \mathrm{El}$ enorme poder fáctico que tienen los sistemas financieros a nivel mundial puede deberse a su capacidad para crear dinero de la nada y a la vez estar respaldados y protegidos por los gobiernos soberanos. 4 Habría que cuestionarse cuán competitivo es el sistema bancario en Ecuador, donde, a junio de 2014, apenas cuatro bancos concentraron el $63 \%$ de todos los activos del total de bancos.

5 En Ecuador, por ejemplo, a junio de 2014, apenas cuatro bancos concentraron el 63\% de todos los activos del total de bancos (Superintendencia de Bancos y Seguros, 2014).

\section{BIBLIOGRAFÍA}

Bell, S. (1998, agosto 8). Can taxes and bonds finance government spending? Levy Economics Institute. Recuperado de: http://estes.levy.org/pubs/wp244.pdf

Bell, S. (2001, mayo 5). The role of the state and the hierarchy of money. Cambridge Journal of Economics. Recuperado de: http://cas.umkc.edu/economics/people/facultyPages/wray/courses/Econ\%20 601 /readings/Bell\%20The\%20Role\%20of\%20the\%20State\%20and\%20the\%20Hierarchy\%20 of\%20Money.pdf

CBS. (2009, abril 18). Entrevista a Ben Bernanke. Recuperado de: http://www.youtube.com/watch?v=od PfHY4ekHA

Forstater, M. (1999, abril 13). Functional Finance and Full Employment: Lessons from Lerner for Today? Levy Economics Institute. Recuperado de: http://www.levyinstitute.org/pubs/wp272.pdf

FRED. (2014, junio 2015). Federal Reserve Economic Data. Recuperado de: http://research.stlouisfed. org/fred2/ 
Fullwiler, S. (2008). Modern Central Bank Operations - The General Principles. Social Science Research Network SSRN. Recuperado de: http://papers.ssrn.com/sol3/papers.cfm?abstract_id=1658232 Fullwiler, S. (2013). An endogenous money perspective on the post-crisis monetary policy debate. Review of Keynesian Economics. Recuperado de: http://www.rokeonline.com/roke/post\%20crisis\%20 monetary\%20policy\%20debate. pdf

Innes, A. M. (1913, febrero 14). What is Money. The Banking Law Journal. Recuperado de: https://www. community-exchange.org/docs/what\%20is\%20money.htm

Innes, A. M. (1914, febreo 14) The Credit Theory of Money. The Banking Law Journal. Recuperado de: https://www.community-exchange.org/docs/The\%20Credit\%20Theoriy\%20of\%20Money.htm

Knapp, G. F. (1914, febrero 14). The State Theory of Money. Recuperado de: http://socserv2.socsci.mcmaster.ca/econ/ugcm/3ll3/knapp/StateTheoryMoney.pdf

Keen, S. (2014). Secular stagnation and endogenous money. Real world economics review, issue 66: Recuperado de: http://www.paecon.net/PAEReview/issue66/Keen66.pdf

Lavoie, M. (2000). A Primer on Endogenous Credit-money. University of Ottawa. Recuperado de: http:// aix1.uottawa.ca/ robinson/Lavoie/Courses/2007_ECO6183/childguide4.pdf

Lavoie, M. (2011). The monetary and fiscal nexus of neo-chartalism: A friendly critical look. University of Ottawa. Recuperado de: http://www.boeckler.de/pdf/v_2011_10_27_lavoie.pdf

Lerner, A. (1943, abril 17). Funtional Finance and the Federal Debt. En: Selected Economic Writing of Abba Lerner. Recuperado de: http://k.web.umkc.edu/keltons/Papers/501/functional\%20finance.pdf

McCulley, P. (2009). The Shadow Banking System and Hyman Minsky's Economic Journey. PIMCO. Recuperado de: http://www.pimco.com/en/insights/pages/global\%20central\%20bank\%20 focus\%20may\%202009\%20shadow\%20banking\%20and\%20minsky\%20mcculley.aspx

McLeay, M., Radia, A., y Thomas, R. (2014). Money creation in the modern economy. Bank of England. Recuperado de: http://www.bankofengland.co.uk/publications/Documents/quarterlybulletin/2014/qb14q1prereleasemoneycreation.pdf

Minsky, H. (1986). Stabilizing an Unstable Economy. New York, USA: Mc Graw Hill.

Minsky, H. (2011, septiembre 23). Uncertainty and the Institutional Structure of Capitalist Economies: Remarks upon Receiving the Veblen-Commons Award. Journal of Economic Issues. Recuperado de: http://www.jstor.org/stable/4452235

Mosler, W. y Forstater, M. (2005). General framework for the analysis of currencies and commodities. UMKC. Recuperado de: http://cas.umkc.edu/econ/economics/faculty/Forstater/papers/ BookChaptersEnclopediaEntries/ GeneralFrameworkAnalysisOfCurrenciesCommidities.pdf

Tcherneva, P. (2013, mayo 13). Chartalism and the tax-driven approach to money. En Arestis P. y Malcolm S. (Ed.) 'A handbook of Alternative Monetary Economics'. Edward Elgar Publishing Limited. Cheltenham - UK. Recuperado de: http://www.cfeps.org/ss2008/ss08r/Tcherneva/ Tcherneva-Ch\%2005-Arestis-Sawyer\%20volume.pdf

Wray, R. (2007). A Post-Keynesian View of Central Bank Independence, Policy Targets, and the Rulesversus-Discretion Debate. Levy Economics Institute. Recuperado de: http://www.levyinstitute.org/ publications/a-post-keynesian-view-of-central-bank-independence-policy-targets-and-the-rules-versus-discretion-debate 
Wray, R. (2014, febrero 7). Money. Levy Economics Institute. Recuperado de: http://www.levyinstitute. org/publications/money

Wray, R. (2012). Modern Money Theory. New York, USA: Palgrave Macmillan. 